\title{
Culture and Medicine
}

\section{Myths and medicine}

In this issue, WJM starts an ongoing series called Medical Myths. We aim to encourage readers to evaluate critically even the most standard and widespread practices, when they are based on tradition and the weight of authority, but in the absence of, or contrary to, available evidence.

Although our use of the term myth does not necessarily imply all the elements of classical mythology, it is appropriate because mythological medical practices may well arise from the same social needs, and serve a similar purpose, as cultural mythology. In the larger sense, myths are shared stories that arise and live for generations, initially in oral tradition, but eventually taking on new life in literary versions created by poets, journalists, and historians (or textbook authors). Myths seem to respond to profound communal needs, most often including the need to justify existing power relations, whether they be between gods and humans, the community and the individual, men and women, parents and children, teachers and students, or specialists and generalists. Myths try to assure us that our experiences are shared, and they can function as a means of social control and certification of legitimacy.

Myth does its work in the heart and can therefore be more powerful than the logic to which it has always been opposed. Poets like Homer were the first great mythologists, but myth plays a role in all aspects of communal life. Great logicians-like Plato, for example-frequently recognized this, and deployed mythos to support their abstract logos, which they thought most people would never be able (or even want) to comprehend. Politicians, throughout history, have used and manipulated mythology to win support for projects the underlying logic of which might be otherwise unappealing. Hitler used the Greek myth of racial purity with enormous success, and the feuding aristocracy of Europe, in World War I, relied on myths of nationalistic pride, religious hatred, and racial superiority to help convince the poor of their countries to murder each other by the millions. Modern politicians exploit all types of mythology—from ancient Biblical "promises" about land, to religious pronouncements about the "proper" relationship between men and women, to memories of glorious past battles against brutal enemies, to nationalistic concepts of racial or ethnic unworthiness - to further their ends. Readers can surely think of many of the ways in which myth is used today to incite group hatred, or attack protest, or innovation, or any real challenge to the status quo.

Medicine, too, has long been the subject of mythology.
The Greeks and Romans created myths about the first physician, Asklepios (or Aesculapius), a son of Apollo. The Greeks believed that all human skills came from the gods, and by tying medicine to such an important god as Apollo, they invested it with great power and importance. Asklepios' two sons were included by Homer as heroic warriors in the Trojan War, thus conferring aristocratic status on physicians, who as a group became known as Sons of Asklepios.

Early Greek and Roman poems told mythological tales about medicine and healers. The first such poem, the anonymous Hymn to Asklepios, hails this first physician as a "great source of delight to human beings," one who "charms away pain." Similarly, the great poet Pindar calls him the "gentle architect of pain relief." Although Greek healers could not easily claim to prolong life, they attained heroic status nonetheless. On the other hand, when Pindar's Asklepios (and by extension all physicians) overstepped his bounds by reviving a dead man, he was blasted to Hades by Zeus' thunderbolt, reminding us of the danger of pride (bubris), such as is reflected by a physician's attempt to be god-like (by cheating death).

Medical myths based on authoritarian dictates, in the absence of or contrary to evidence, must also serve a similar need. The first myth we will cover is the prohibition of analgesia for patients with a possible surgical cause of abdominal pain-a telling example (see p 209). Restriction of pain relief-relief of pain being the very core of what healers have always done and for which they have always been exalted (as the Greek myths remind us) - seems clearly antithetical to the interests of both physicians and their patients. How could an authority like Cope have propounded this contrarian principle so forcefully, and he and his disciples inculcated it so successfully throughout the profession, in the absence of any evidence? Whose interests did it (and does it still) serve? Why do physicians of all stripes continue to underuse analgesics, not only in the setting of acute abdominal pain, but also in so many other areas of medicine, based on discredited concepts (but ongoing mythology) about "creating addicts," and "drug-seekers" and "obscuring diagnosis"?

Mythology in general plays to our hearts, to get us to believe things for which logic or evidence is lacking. When myths convince us to act in ways that are contrary to our own interests, or (for healers) to the interests of patients, we must first recognize them for what they are, then critically challenge their assumptions, and finally, have the courage to abandon them. 


\section{Medical Myth}

\section{Analgesia should not be given to patients with an acute abdomen because it obscures the diagnosis}

Surgical tradition holds that the use of analgesics should be withheld from patients with acute abdominal pain until a diagnosis and management plan have been established by a surgeon. This belief originated early in this century ${ }^{1}$ and was emphasized by Cope in his extremely influential book, Early Diagnosis of the Acute Abdomen. Cope claimed that analgesia would mask signs and symptoms, delay diagnosis, and lead to increased morbidity and mortality. ${ }^{2}$ In the most recent edition of Cope's book, Silen condemns the practice of withholding pain medication from a patient with acute abdominal pain. In the next sentence, however, he states that analgesia medication should be given only after a "responsible surgeon" takes a thorough history and performs a thorough physical examination. In actual practice, a surgeon is rarely the first physician to examine a patient with acute abdominal pain, and surgical consultation can take many hours. Given that all the evidence in the medical literature suggests that the use of narcotic analgesia does not obscure diagnosis - and may even improve diagnostic accuracy - in such patients, the traditional practice of withholding pain medication in patients with substantial pain should be seen as inappropriate and inhumane.

Currently five prospective randomized studies in the literature address the use of pain relief in patients with acute abdominal pain. ${ }^{3-7}$ Although study methods vary to some degree, all patients were randomly assigned to receive narcotic analgesia or placebo, and all studies used variations of visual analog scales to evaluate pain before and after patients received medication. All the studies then compared the accuracy of the clinician's diagnosis and treatment in patients who did or did not receive narcotics; four of the studies used a double-blind design.

Attard and coworkers performed a randomized double-blind study ${ }^{3}$ and found that the early administration of opiate analgesics to patients with acute abdominal pain relieved discomfort without compromising diagnosis or treatment. One hundred patients were given either intramuscular papaveretum (a combination of morphine, codeine, and papaverine not available in the US) or placebo, and pain and tenderness scores were substantially reduced in the group receiving an opiate compared with those receiving placebo. There was no difference between the groups in the localization of physical signs, and there was $100 \%$ confidence in the surgical registrar's management plan in both groups. The decision whether to per- form surgery was ultimately found to be incorrect in only two patients given narcotics compared with nine patients given placebo.

Pace and colleagues, in another double-blind, placebocontrolled study involving 75 patients, found that intravenous morphine sulfate effectively relieved pain and did not alter physicians' ability to evaluate accurately and treat patients appropriately. ${ }^{4}$ Patients received titrated intravenous doses of morphine of as much as $20 \mathrm{mg}$. Three diagnostic or management errors occurred in each group.

LoVecchio and associates also found that the early intravenous administration of 5 to $10 \mathrm{mg}$ of morphine did not affect the diagnosis or treatment of patients with acute abdominal pain. ${ }^{5}$ The use of morphine was associated with some change in tenderness and localization in half the patients but led to no delays in care or eventual morbidity.

In a study by Vermeulen and colleagues, morphine was used to evaluate the effect of early pain relief on US physicians' performance and surgical decision making. ${ }^{6}$ The use of morphine improved pain compared with that of placebo and was not found to change the appropriateness of the surgeons' decision making.

Zoltie and Cust randomly assigned patients with acute abdominal pain to receive sublingual buprenorphine hydrochloride or placebo. ${ }^{7}$ Buprenorphine use in this study was found to be no better than placebo for relieving pain; however, its use showed a tendency to localize tenderness while in no way obscuring the final diagnosis.

Thus, all five studies addressing the effects of analgesia on diagnosis and treatment in patients with acute abdominal pain failed to produce any evidence that this practice is harmful. All of these studies, which together involved 748 patients, concluded that the appropriate use of analgesia can effectively decrease pain to a greater degree than it does the localization of tenderness, while possibly even facilitating the ability to make an accurate diagnosis.

Even given this information, the concern has been raised that the use of narcotics can interfere with surgeons' ability to obtain informed consent if an operation or other procedure is required. This concern is unfounded for a number of reasons. First of all, informed consent requires (among other things) that the patient be capable of evaluating the information in a rational manner and then making an informed decision. Although it is possible to give so much narcotic medication that it interferes with a patient's
G Scott Brewster

Emergency Medicine Residency Program Mel E Herbert

Department of Emergency Medicine Olive View-UCLA Medical Center 14445 Olive View Drive, North Annex Sylmar, CA 91342 Jerome R Hoffman

Emergency Medicine Center

924 Westwood Blvd Los Angeles, CA 90095

Correspondence to:

Dr Brewster

Gbrewste@ucla.edu

Competing interests: None declared

West J Med 2000;172:209-210 
cognitive function, this rarely occurs when medication is given in the amounts needed to relieve acute pain. Most patients who have received narcotics before urgent abdominal surgery feel that they were capable of giving informed consent, despite their medications. In a patient in whom analgesia produces excessive sedation, reversal agents can be used, although this step is rarely needed and should be done with great caution because it can exacerbate pain.

Finally, it could be argued that informed consent is impossible in the absence of analgesia, for two reasons. First, severe pain can impair patients' judgment, so that they are incapable of making truly informed decisions. Second, and perhaps most important, withholding analgesia until consent is signed can rightly be viewed as coercion because patients are led to understand that the relief of pain will only be initiated when the consent form has been signed.

The traditional teaching of withholding pain medication in patients with acute abdominal pain stems from a time when medicine was without modern diagnostic tech- niques and when the intravenous titration of opiates was not routinely practiced. Early and appropriate pain relief for patients with acute abdominal pain is humane, does not adversely affect diagnostic acumen or clinical decision making, and should be considered part of the initial management of every such patient.

References

1 Hughes TJ. Opiates in acute abdominal pain [letter]. BMJ 1979;2(6198): 1145 .

2 Silen W. Cope's early diagnosis of the acute abdomen. 19th edition. New York (NY): Oxford University Press; 1996.

3 Attard AR, Corlett MJ, Kidner NJ, et al. Safety of early pain relief for acute abdominal pain. BMJ 1992;305:554-556.

4 Pace S, Burke TF. Intravenous morphine for early pain relief in patients with acute abdominal pain. Acad Emerg Med 1996;3:1086-1092.

5 LoVecchio F, Oster N, Sturmann K, et al. The use of analgesics in patients with acute abdominal pain. J Emerg Med 1997;15:775-779.

6 Vermeulen B, Morabia A, Unger PF, et al. Acute appendicitis:

influence of early pain relief on the accuracy of clinical and US findings in the decision to operate- a randomized trial. Radiology 1999;210:639-643.

7 Zoltie N, Cust MP. Analgesia in the acute abdomen. Ann R Coll Surg Engl 1986;68:209-210.

\section{Adolescent sexuality and the media: a review of current knowledge and implications}

Enid Gruber
Department of
Psychiatry and
Biobehavioral Sciences
University of California
Los Angeles, CA 90095
Joel W Grube
Prevention Research
Center
2150 Shattuck Ave,
Suite 900
Berkeley, CA 94704
Funding: This work was
supported in part by
grant AA12136 from the
National Institute on
Alcohol Abuse and
Alcoholism
Correspondence to:
Dr Grube
Grube@prev.org
2000;172:210-214

There is growing concern about young people's exposure to sexual content through television and other electronic media and about its potential effects on their sexual attitudes, beliefs, and behaviors. Researchers have documented the growing prevalence of sexual talk and portrayals of sexual behavior in televised media, as well as associations between adolescent viewing patterns and their sexual activities. ${ }^{1-7}$

\section{METHODS}

We reviewed the current scientific literature on adolescents and sex in the media—using searches of MEDLINEand the psychological and media literature. The emphasis was on rigorous research and included accessing the expertise of health care professionals and other knowledgeable sources on the media. These sources included the Kaiser Family Foundation, Menlo Park, California; the Center for Media Education (Washington, DC); and professional societies and organizations from medicine, psychiatry, and psychology. The available research does not adequately address the effects of exposure to sexual content

\section{Summary points}

- Adolescents are exposed to many sexual images and messages on television that are almost universally presented in a positive light with little discussion of potential risks and adverse consequences

- Adolescents use the media as sources of information about sex, drugs, AIDS, and violence as well as to learn how to behave in relationships

- Research indicates that adolescent sexuality is associated with media use, but the direction of the relationship is not clear

- Practitioners should address preadolescent and adolescent patients' use of electronic media and the Internet, television viewing patterns, and R- and $\mathrm{X}$-rated movie attendance or video rentals when assessing risk behavior for a thorough medical history

- Parents and guardians should be encouraged to supervise adolescents' media use, take advantage of the "V chip" and screening software to reduce inappropriate access, and help teenagers to critique what they see in the media 
in the media on adolescent beliefs, knowledge, intentions, and behaviors. Similarly, research on sexual content of the Internet, in video games or other handheld devices, or in the multitude of other electronic media has been scant. ${ }^{7}$

\section{SEXUALITY IN THE MEDIA}

Although sexual content in the media can affect any age group, adolescents may be particularly vulnerable. Adolescents may be exposed to sexual content in the media during a developmental period when gender roles, sexual attitudes, and sexual behaviors are being shaped. ${ }^{1}$ This group may be particularly at risk because the cognitive skills that allow them to critically analyze messages from the media and to make decisions based on possible future outcomes are not fully developed.

Analyses of broadcast media content indicate that, on average, teenaged viewers see 143 incidents of sexual behavior on network television at prime time each week, ${ }^{8}$ with portrayals of three to four times as many sexual activities occurring between unmarried partners as between spouses. ${ }^{9}$ As much as $80 \%$ of all movies shown on network or cable television stations have sexual content. ${ }^{2}$ An analysis of music videos indicates that $60 \%$ portray sexual feelings and impulses, and a substantial minority display provocative clothing and sexually suggestive body movements. ${ }^{10}$ Analyses of media content also show that sexual messages on television are almost universally presented in a positive light, with little discussion of the potential risks of unprotected sexual intercourse and few portrayals of adverse consequences. ${ }^{11,12}$

Survey data show that adolescents' access to and use of media as sources of information are substantial. In a national study, ${ }^{8}$ high school students reported an average of 2.9 television sets, and 1.3 of 10 (13\%) of American children reported living in homes with two or more televisions, $97 \%$ had videocassette recorders in their homes, $75 \%$ had access to cable television, and more than half had a television set in their own rooms. ${ }^{7}$ Further, more than $80 \%$ of adolescents report that their peers find out some or a lot about sex, drugs, and violence from television shows, movies, and other entertainment media. ${ }^{13}$ About $10 \%$ of teens acknowledge that they have learned more about the acquired immunodeficiency syndrome (AIDS) from these media sources than from parents, school personnel, clergy, or friends. ${ }^{13}$

\section{ADOLESCENT SEXUALITY AND CONSEQUENCES}

Policy makers and health professionals have long been concerned about premarital sexual activity in the teenaged population and the risks of pregnancy and sexually transmitted diseases, including infection with the human immunodeficiency virus (HIV). ${ }^{14,15}$ Nationwide, nearly half

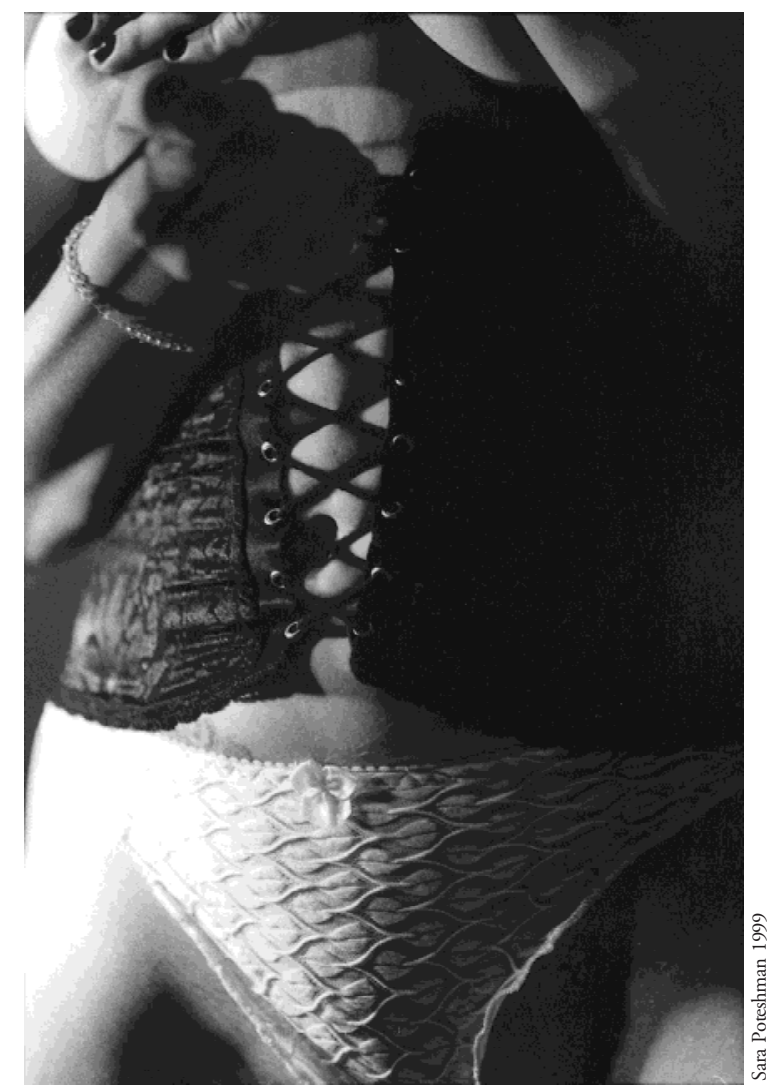

of all high school students have had sexual intercourse, ${ }^{12}$ with African Americans significantly more likely to be sexually experienced $(72 \%)$ than Hispanics $(52 \%)$ or whites (47\%). ${ }^{16}$ Research suggests that even among teenagers who have not experienced vaginal intercourse, substantial numbers engage in other intimate sexual behaviors that carry health risks. ${ }^{17}$

Among adolescent girls in the United States aged between 15 and 17 years, 75 per 1,000 become pregnant each year, ${ }^{18}$ a rate two to seven times higher than rates in other industrialized nations. ${ }^{19}$ Those adolescents (19\% of the adolescent population) who report four or more lifetime sexual partners are at greater risk for contracting sexually transmitted diseases, including HIV infection. ${ }^{20}$ Overall, $25 \%$ of sexually active teenagers and $13 \%$ of all adolescents between the ages of 13 and 19 become infected with sexually transmitted diseases each year, representing 3 million cases or about $25 \%$ of all new cases reported annually. ${ }^{21}$

\section{WHAT WE KNOW ABOUT SEXUAL CONTENT IN THE MEDIA}

What we know about the potential effects of televised sexual content on adolescents is based largely on content analyses of media that quantify levels of sexual material 
and track trends from year to year. ${ }^{4,22}$ This work includes studies of network and cable programming, ${ }^{2,4}$ rock music and music videos, ${ }^{23}$ and $\mathrm{R}$ - and X-rated films available on videocassette. $^{24}$

In addition to content analyses, correlational studies have linked sociodemographic factors (for example, sex, age, and ethnicity) to adolescents' viewing preferences and to their understanding and interpretation of sexual material in the media. Findings indicate that adolescent girls choose network television programs with sexual content more often than do adolescent boys ${ }^{25}$ and spend more time watching it, often in the company of parents. ${ }^{5}$ Older adolescent boys, however, are more oriented to the hardcore sexual content found in explicit music lyrics and Xrated films. ${ }^{3}$ They are also more drawn to new media choices like handheld devices, the Internet, and computer games. $^{22}$ Adolescents of both sexes who watch and listen to a lot of media are more likely to accept stereotypes of sex roles on television as realistic than are less frequent viewers. $^{26}$

Other research indicates that ethnicity plays an important role in media viewing choices. Compared with their white peers, African Americans spend more time watching television, are more likely to choose fictional programming with African American characters, and are more likely to perceive those characters as realistic. ${ }^{27}$ Similarly, African American adolescents report watching more Rrated movies than white peers, with less parental involvement or mediation. ${ }^{27}$ African American and white youths also find different features of video portrayals salient and disagree on story elements. ${ }^{28}$ Higher rates of viewing by adolescent African American adolescents, especially of soap operas, make them more likely to see sexual con-

Table 1 Resources for further information on adolescents and the media

\begin{tabular}{|c|c|c|}
\hline Author/Sponsor & Title/Publication & Web Address/Telephone \\
\hline $\begin{array}{l}\text { American Academy of } \\
\text { Pediatrics }\end{array}$ & $\begin{array}{l}\text { Sexuality, contraception, } \\
\text { and the media: Policy } \\
\text { Statement. Pediatrics } \\
\text { 1995;95:298-300 }\end{array}$ & $\begin{array}{l}\text { www.aap.org/policy/ } \\
\text { o0657.html } \\
\text { tel: (847) 228-5005 }\end{array}$ \\
\hline $\begin{array}{l}\text { Center for Media Education } \\
\text { and Henry J Kaiser } \\
\text { Family Foundation }\end{array}$ & $\begin{array}{l}\text { A parent's guide to the TV } \\
\text { ratings and V-chip }\end{array}$ & $\begin{array}{l}\text { www.vchipeducation.org } \\
\text { tel: (202) 331-7833 }\end{array}$ \\
\hline \multirow[t]{2}{*}{ Children Now } & $\begin{array}{l}\text { Research reports on } \\
\text { children and the media }\end{array}$ & $\begin{array}{l}\text { www.childrenow.org } \\
\text { tel: }(510) 763-2444\end{array}$ \\
\hline & $\begin{array}{l}\text { Talking with kids about } \\
\text { tough issues }\end{array}$ & $\begin{array}{l}\text { www.talkingwithkids.org } \\
\text { tel: (510) } 763-2444\end{array}$ \\
\hline $\begin{array}{l}\text { National Center for Missing } \\
\text { and Exploited Children } \\
\text { and Larry Magid }\end{array}$ & $\begin{array}{l}\text { Teen safety on the } \\
\text { information highway } \\
\text { (free brochure) }\end{array}$ & $\begin{array}{l}\text { www.safeteens.com } \\
\text { tel: }(800) 843-5678\end{array}$ \\
\hline $\begin{array}{l}\text { American Academy of Child } \\
\text { and Adolescent } \\
\text { Psychiatry }\end{array}$ & $\begin{array}{l}\text { The influence of music } \\
\text { and rock videos }\end{array}$ & $\begin{array}{l}\text { www.aacap.org/publications/ } \\
\text { factsfam/musicvid.html } \\
\text { tel: (202) 996-7300 }\end{array}$ \\
\hline
\end{tabular}

tent. $^{26,27}$ Comparable data are not available on Asian, Latino, or other ethnic subgroups.

Age or stage of development also influences comprehension and interpretation of sexual content. In a study of sexual innuendo on television, ${ }^{29} 12$-year-old youths were less likely to understand suggestive material than 14- and 16-year-olds. Similarly, in a qualitative study of adolescent girls aged 11 to 15 , those who were at an earlier stage of physiologic development were less interested in sex portrayed in the media whereas more mature young women were intrigued and more actively sought out sexual content in the media as a means of "learning the rules, rituals, and skills" of romance and relationships. ${ }^{30}$ Specifically, they reported that the media provided models for achieving the "right look" to become popular and attract boys, portrayed teen characters with problems similar to their own, showed how they solved those problems, and gave examples of how to behave in sexual situations. We could not find comparable studies of developmental influences on boys' understanding and interpretation of sexual content.

A few studies have assessed the associations between the degree and nature of adolescent exposure to sexual content and their sexual attitudes and behaviors. A recent study of African American girls aged 14 to 18 years found that teens with either multiple sexual partners or a history of sexually transmitted infections reported a higher rate of viewing television shows that depicted women as sexual objects or prizes. ${ }^{31} \mathrm{~A}$ few experimental studies have shown that viewing sexual content can have moderate effects on sexual knowledge or attitudes, ${ }^{29,32,33}$ but it is unclear whether these effects are sustained over time or result in changes in sexual intentions or behavior. Brown and Newcomer $^{34}$ found that television viewing patterns differed by the sexual status of the adolescent (virgin versus sexually active), with sexually active teens viewing more television with a high level of sexual content. Determining whether exposure to sexual content encouraged sexual experimentation, or vice versa, was not possible. This is a key unanswered question because of the lack of longitudinal research in this field.

Many theories have been advanced to explain the effects of media on behavior. ${ }^{6}$ They are all based on the fundamental notion that greater exposure to the media leads to the adoption of the values, beliefs, and behaviors that are portrayed, particularly when they are shown to be reinforced or are unaccompanied by adverse consequences. Research on exposure to violent content in the media provides some support for these views. ${ }^{23,35}$ Sexual activity, however, may not be learned by observation and modeling in the same way as aggression or violence. Other promising work appears in research on televised alcohol advertising and adolescent drinking. ${ }^{36,37}$ Findings suggest that simple exposure to alcohol advertisements does not 
affect alcohol use. Rather, the effects of alcohol advertisements depend on the extent to which young people like and attend to them. Music and humor are key elements in determining liking and attention. Importantly, this research used statistical modeling that showed that attention to alcohol advertising increases adolescent drinking, whereas drinking does not influence attention to alcohol advertising.

\section{APPROACHES WITH ADOLESCENTS AND PARENTS}

Although research lags behind technology, resources are available that support interventions by medical professionals, parents, and others (table 1). Physicians should address preadolescent and adolescent patients' use of electronic media and the Internet, television viewing patterns, and viewing of $\mathrm{R}$ - or $\mathrm{X}$-rated movies or videos when taking a thorough medical history to assess for risk behavior and as a mechanism for discussing sexual knowledge and plans.

No guidelines exist on the recommended amount of time that adolescents should spend viewing television or other media. For many parents and physicians, the ba- rometer of overuse is an amount greater than we or our children use the media. The main concern for practitioners should be whether television or other electronic media use is interfering with an adolescent patient's ability to function effectively in other spheres of life. Does media viewing cut into homework time or other recreational activities like athletics or hobbies? Are teenagers absorbed in long hours of solitary viewing or game playing in their bedrooms without supervision or oversight? Are they modeling their behavior on that of performers or dramatic characters? Is this behavior inappropriate or harmful for their age or stage of development? Are adults aware of the media influence? Asking adolescents about their media viewing can give the physician or parent the opportunity to detect any feelings of depression or alienation. The adolescent may reveal unrealistic expectations about physical attractiveness and unhealthy dieting and exercise practices. Suggested areas for inquiry are presented in table 2 .

The importance of supervision and guidance in the media choices of adolescents and their volume of use should be emphasized to parents and concerned adults. Joint viewing or participation may be the best option. When joint viewing is not possible, parents and guardians

Table 2 Questions to ask adolescents about their use of the media, issues to address, and concerns

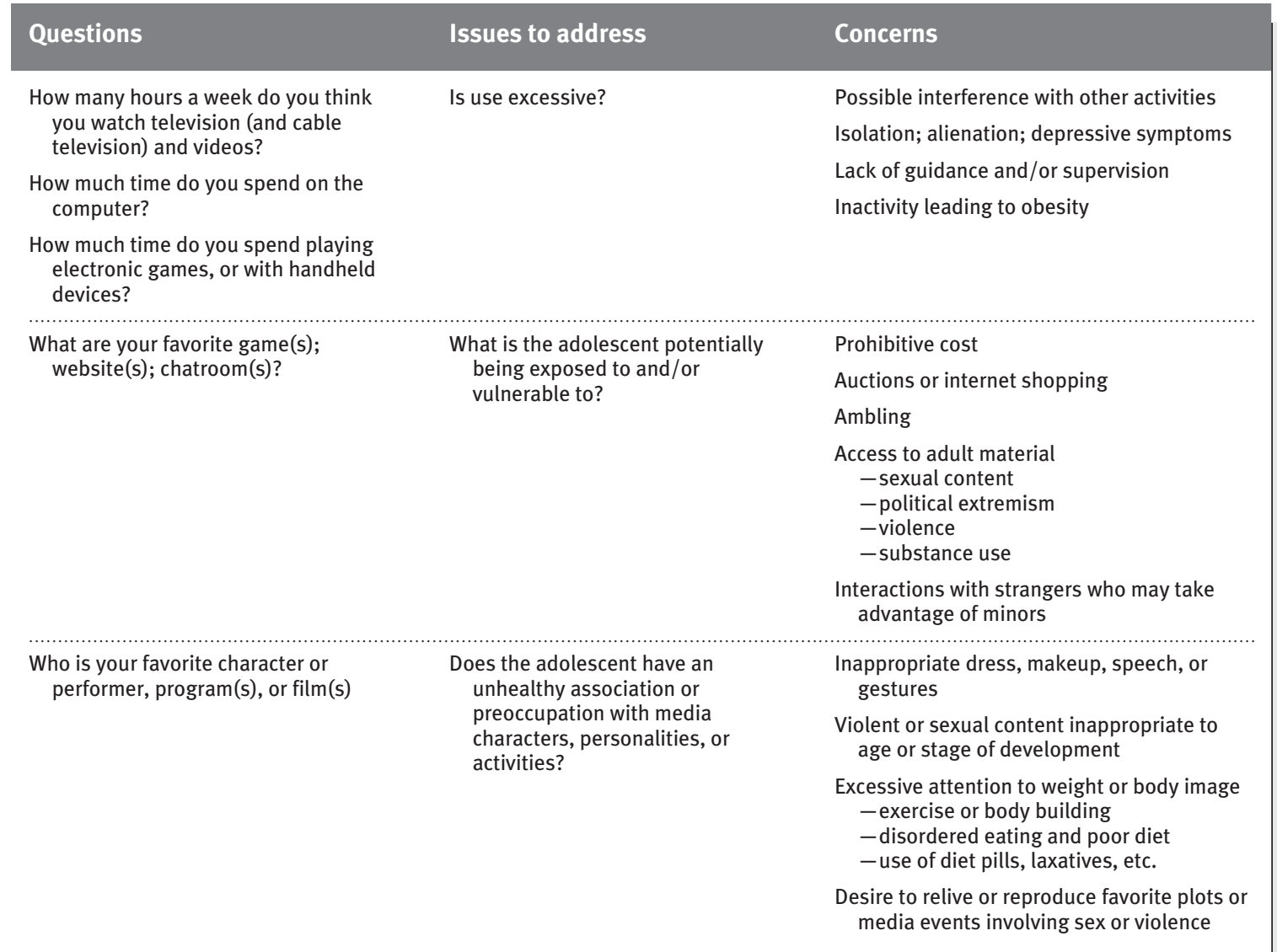


should be encouraged to take advantage of the television $\mathrm{V}$ chip and screening software for computers to reduce inappropriate access. Finally, adults in all areas of adolescents' lives need to help teenagers critically evaluate the media and it's often unrealistic representation of characters, products, behavior, and life situations. Teaching adolescents to be critical consumers of electronic media is the best prevention strategy.

\section{CONCLUSIONS}

Simple exposure to sexual content in the media will not make teens deny or ignore values and information they have absorbed from families, school, religious teachings, and other respected adults. Longitudinal studies of young people could provide a better understanding of how sexual portrayals in the media are integrated into adolescents' beliefs about the risks and rewards of engaging in sex and their intention to act on these beliefs. Future research must also take into account the importance of parental involvement in adolescents' use of the media, the degree of adolescents' understanding of the unreal nature of the media, teens' possible identification with fictional characters or highly visible media personalities, the norms modeled by parents and peers, and adolescents' own understanding of the consequences of health risk behaviors.

\section{References}

1 Committee on Communications, American Academy of Pediatrics. Sexuality, contraception and the media. Pediatrics 1995;95:298-300.

2 Kunkel D, Cope KM, Maynard-Farinola WJ, et al. Sex on TV: content and context. Menlo Park (CA): Kaiser Family Foundation; 1999.

3 Buerkel-Rothfuss NL, Strouse JS, Pettey G, et al. Adolescents' and young adults' exposure to sexually oriented and sexually explicit media. In: Greenberg BS, Brown JD, Buerkel-Rothfuss NL, eds. Media, sex and the adolescent. Cresskill (NJ): Hampton Press; 1993:99-112.

4 Huston AC, Wartella E, Donnerstein E. Measuring the effects of sexual content in the media: a report to the Kaiser Family Foundation. Menlo Park (CA): Kaiser Family Foundation; 1998

5 Brown JD, Greenberg BS, Buerkel-Rothfuss NL. Mass media, sex, and sexuality. Adolesc Med 1993;4(pt 1):511-552.

6 Brown JD, Steele JR. Sex and the mass media. Menlo Park (CA): Kaiser Family Foundation; 1995

7 Roberts DF, Foehr UG, Rideout VJ, et al. Kids \& media @ the new millennium. Menlo Park (CA): Kaiser Family Foundation; 1999

8 Louis Harris \& Associates, Inc. Sexual material on American network television during the 1987-88 season. New York (NY): Planned Parenthood Federation of America; 1988.

9 Greenberg BS, Stanley C, Siemicki M, et al. Sex content on soaps and prime-time television series most viewed by adolescents. In: Greenberg BS, Brown JD, Buerkel-Rothfuss NL, eds. Media, sex and the adolescent Cresskill (NJ): Hampton Press; 1993:29-44.

10 Baxter RL, De Riemer C, Landini A, et al. A content analysis of music videos. J Broadcast Electronic Media 1985;29:333-340.

11 Lowry DT, Towles DE. Prime time TV portrayals of sex, contraception, and venereal diseases. Journalism Q 1989;66:347-352.

12 Lowry DT, Towles DE. Soap opera portrayals of sex, contraception, and sexually transmitted diseases. J Commun 1989;39:76-83.

13 Kaiser Family Foundation/Children Now. Talking with kids about tough issues: a national survey of parents and kids. Menlo Park (CA): Kaiser Family Foundation; 1999.

14 Hofferth SL, Kahn JR, Baldwin W. Premarital sexual activity among
U.S. teenage women over the past three decades. Fam Plann Perspect 1987;19:46-53.

15 Centers for Disease Control and Prevention (CDC). Current trends in premarital sexual experience among adolescent women-United States, 1970-1988. MMWR Morb Mortal Wkly Rep 1991;39(51-52):929-932.

16 CDC. Trends in sexual risk behavior among high school students-United States, 1991-1997. MMWR Morb Mortal Wkly Rep 1998;47(36):749-752.

17 Schuster MA, Bell RM, Kanouse DE. The sexual practices of adolescent virgins: genital sexual activities of high school students who have never had vaginal intercourse. Am J Public Health 1996;86:1570-1576.

18 Fleming M. Healthy youth 2000: a mid-decade review. Chicago (Ill): American Medical Association, Dept of Adolescent Health; 1996.

19 Moore KA, Miller BE, Glei D, et al. Adolescent sex contraception and childbearing: a review of recent research. Washington (DC): Child Trends; 1995.

20 CDC. Trends in sexual risk behavior among high school students-United States, 1990, 1991 and 1993. MMWR Morb Mortal Wkly Rep 1995;44:124, 131-132.

21 Ozer EM, Brindis CD, Millstein SG, et al. America's adolescents: are they bealthy? San Francisco: University of California-San Francisco, National Adolescent Health Information Center; 1998.

22 Brown JD. Theoretical overview. In: Greenberg BS, Brown JD, Buerkel-Rothfuss NL, eds. Media, sex and the adolescent. Cresskill (NJ): Hampton Press; 1993:19-25.

23 Rich M, Woods ER, Goodman E, et al. Aggressors or victims: gender and race in music video violence. Pediatrics 1998;101(pt 1):669-674.

24 Greenberg BS, Siemicki M, Dorfman S, et al. Sex content in R-rated films viewed by adolescents. In: Greenberg BS, Brown JD, Buerkel-Rothfuss NL, eds. Media, sex and the adolescent. Cresskill (NJ) Hampton Press; 1993:45-58.

25 Greenberg BS, Linsangan R. Gender differences in adolescents' media use, exposure to sexual content and parental mediation. In: Greenberg BS, Brown JD, Buerkel-Rothfuss NL, eds. Media, sex and the adolescent. Cresskill (NJ): Hampton Press; 1993:134-194.

26 Walsh-Childers K, Brown JD Adolescents' acceptance of sex-role stereotypes and television viewing. In: Greenberg BS, Brown JD, Buerkel-Rothfuss NL, eds. Media, sex and the adolescent. Cresskill (NJ): Hampton Press; 1993:117-133.

27 Greenberg BS. Race differences in television and movie behaviors. In: Greenberg BS, Brown JD, Buerkel-Rothfuss NL, eds. Media, sex and the adolescent. Cresskill (NJ): Hampton Press; 1993:145-152.

28 Brown JD, Schulze L. The effects of race, gender, and fandom on audience interpretation of Madonna's music videos. In: Greenberg BS, Brown JD, Buerkel-Rothfuss NL, eds. Media, sex and the adolescent. Cresskill (NJ): Hampton Press; 1993:264-276.

29 Silverman-Watkins LT, Sprafkin JN. Adolescents' comprehension of televised sexual innuendoes. J Appl Dev Psychol 1983;4:359-369.

30 Brown JD, White AB, Nikopoulou L. Disinterest, intrigue, resistance: early adolescent girls' use of sexual media content. In: Greenberg BS, Brown JD, Buerkel-Rothfuss NL, eds. Media, sex and the adolescent. Cresskill (NJ): Hampton Press; 1993:177-195.

31 Wingood GM, DiClemente RJ. Viewing sexually explicit and violent television and its impact on pregnancy and sexual risk taking among female adolescents. Presented at the annual meeting of the American Public Health Association, Washington, DC, November 15-19, 1998.

32 Bryant J, Rockwell SC. Effects of massive exposure to sexually oriented prime-time television programming on adolescents' moral judgment. In: Zillman D, Bryant J, Huston AC, eds. Media, children and the family: social, scientific, psychological dynamics and clinical perspectives. Hillsdale (NJ): Lawrence Erlbaum; 1994.

33 Fabes RA, Strouse JS. Perceptions of responsible and irresponsible models of sexuality: a correlational study. J Sex Res 1987;23:70-84.

34 Brown JD, Newcomer SF. Television viewing and adolescents' sexual behavior. J Homosex 1991;21:77-91.

35 Comstock G. Television and the American child. New York (NY): Academic Press; 1991.

36 Grube JW, Wallack L. Television beer advertising and drinking knowledge, beliefs, and intentions among schoolchildren. Am J Public Health 1994;84:254-259.

37 Grube JW, Madden PA, Friese B. The effects of television alcohol advertising on adolescent drinking. Poster session presented at the annual meeting of the Research Society on Alcoholism, Washington, DC, June 1996 